\title{
10 HOMEÓSTATOS DE JOSÉ-ALBERTO MARQUES [SEGUIDOS DE TRANSCRIÇÃO TEXTUAL]
}

José-Alberto Marques*

RESUMO: Homeóstatos, de José-Alberto Marques (1965-2002).

PALAVRAS-CHAVE: Homeóstatos. José-Alberto Marques. Poesia Experimental Portuguesa.

*Poeta. E-mail: jose.marques.ex58@gmail.com 


\section{Homeóstato 1}

Fig. 1 - Homeóstato 1, José-Alberto Marques, 1965. Imagem de Operação 1 (1967). Também publicado em Poesia Experimental 2 (1966); Antologia da Poesia Concreta em Portugal (1973); Antologia da Poesia Experimental Portuguesa Anos 60 - 80 (2004).

sem luz. o noite acontece. ventre escuro. sombra: neve. alguém: o leu grito

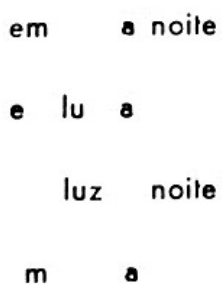

m

。

ventre o. som

som

sombra eu grito

teu grito eu

sem luz

c

- noile

c

ve

m

c $\circ$ m

m o

i

-

90

eu grito

m eu

- m

Texto Digital, Florianópolis, Santa Catarina, Brasil, v. 12, n. 1, p. 144-164, jan./jun. 2016. ISSNe: 1807-9288. 
Descrição/transcrição: 19 iterações do verso "sem luz. a noite acontece. ventre escuro. sombra: neve. alguém: o teu grito":

sem luz. a noite acontece. ventre escuro. sombra: neve. alguém: o teu grito em a noite tece vento. som eu grito

e lua entre som e em teu grito

luz noite ventre sombra: rito

mas

na sombra: neve. alguém: eu

sem luz tece rosto

cé

li

a

a noite cai

vem

comi

go

so vem eu grito

tu

meu

amo

$r$ 


\section{Homeóstato 2}

Fig. 2 - Homeóstato 2, José-Alberto Marques, 1965. Imagem de Operação 1 (1967). Também publicado em Antologia da Poesia Concreta em Portugal (1973).

leu sonho

o teu sonho
ver leus sonhos de lume: $i$ dade
vermelhos reus sonhos de lume: liberdade quente: ossos

Texto Digital, Florianópolis, Santa Catarina, Brasil, v. 12, n. 1, p. 144-164, jan./jun. 2016. ISSNe: 1807-9288. 
Descrição/transcrição: 7 iterações do verso: "vermelhos teus sonhos de lume: liberdade quente: ossos":

vermelhos teus sonhos de lume: liberdade quente: ossos

eu

e

teu sonho

lento

o teu sonho quente

ver teus sonhos de lume: idade

vermelhos teus sonhos de lume: liberdade quente: ossos 


\section{Homeóstato 3}

Fig. 3 - Homeóstato 3, José-Alberto Marques, 1965. Imagem de Operação 1 (1967). Também publicado em Antologia da Poesia Concreta em Portugal (1973); Antologia da Poesia Experimental Portuguesa Anos 60 - 80 (2004).

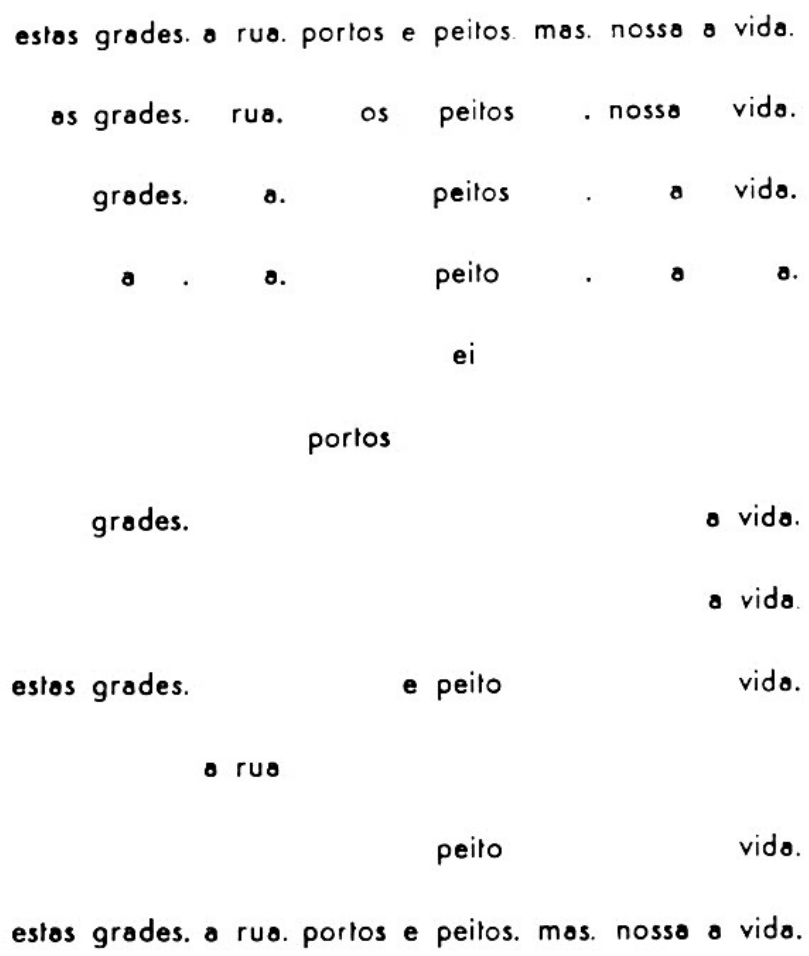


Descrição/transcrição: 12 iterações do verso: "estas grades. a rua. portos e peitos. mas. nossa a vida.":

estas grades. a rua. portos e peitos. mas. nossa a vida.as grades. rua. os peitos. nossa vida.

grades. a. peitos. a vida.

a. a. peito. a a.

ei

portos

grades. a vida.

a vida.

estas grades. e peito vida.

a rua

peito vida.

estas grades. a rua. portos e peitos. mas. nossa a vida. 


\section{Homeóstato 4}

Fig. 4 - Homeóstato 4, José-Alberto Marques, 1965. Imagem de Operação 1 (1967).

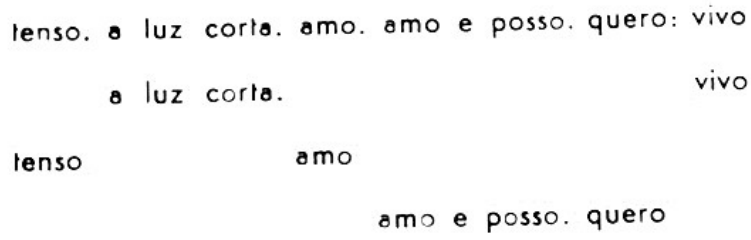


Descrição/transcrição: 5 iterações do verso: "tenso. a luz corta. amo. amo e posso. quero: vivo", transformação em 5 iterações do verso: "força. arde. cor para. o homem. ainda":

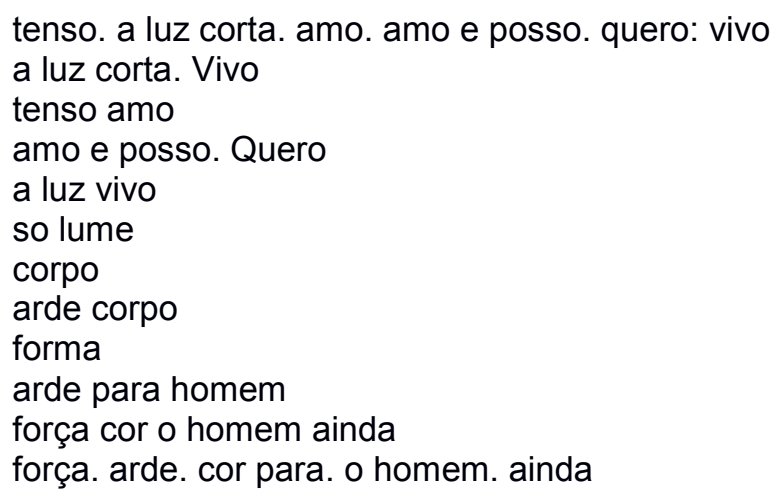




\section{Homeóstato 5}

Fig. 5 - Homeóstato 5, José-Alberto Marques, 1965. Imagem de Operação 1 (1967).

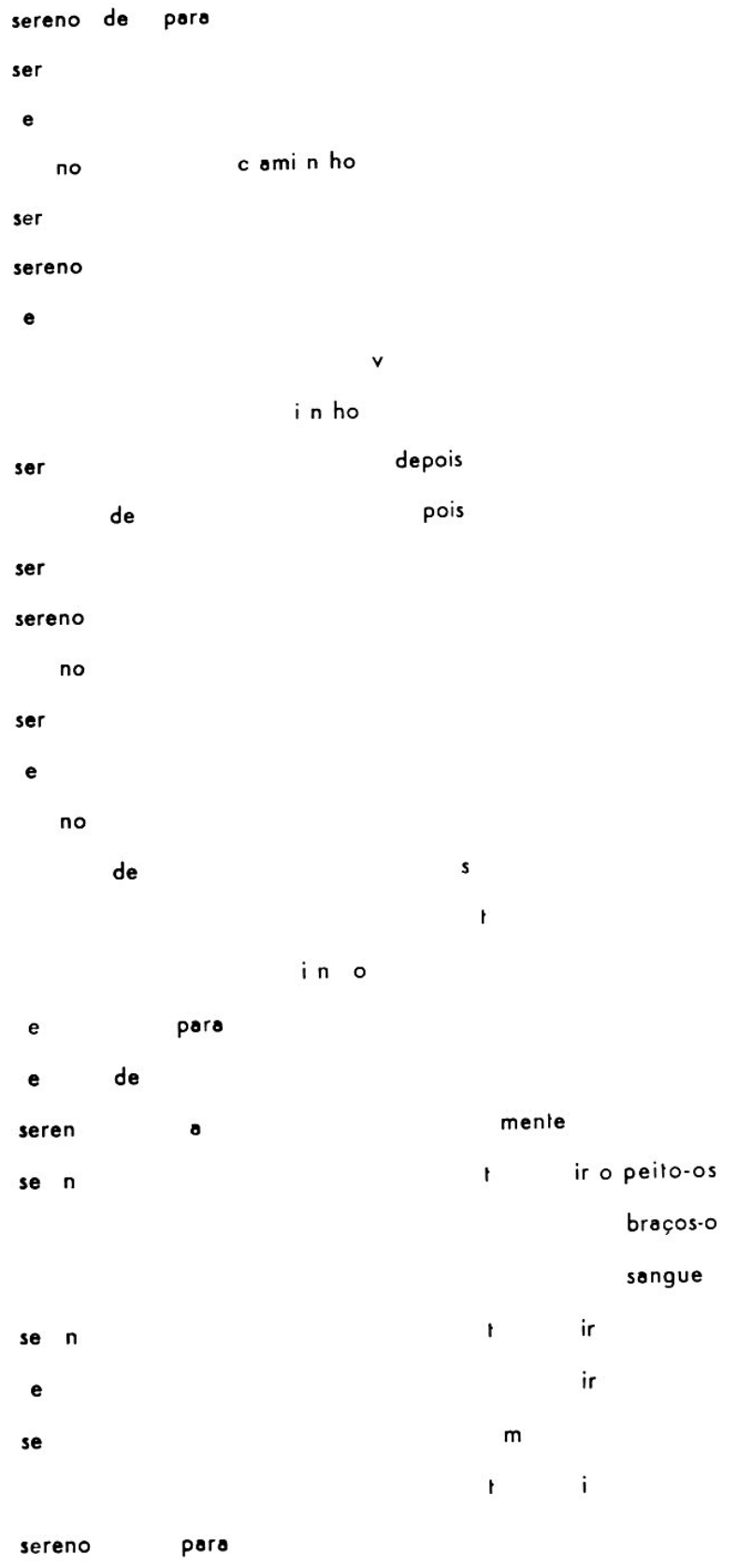

Texto Digital, Florianópolis, Santa Catarina, Brasil, v. 12, n. 1, p. 144-164, jan./jun. 2016. ISSNe: 1807-9288. 
Descrição/transcrição: 31 iterações do verso: "sereno de para caminho depois mente ir o peito-os":

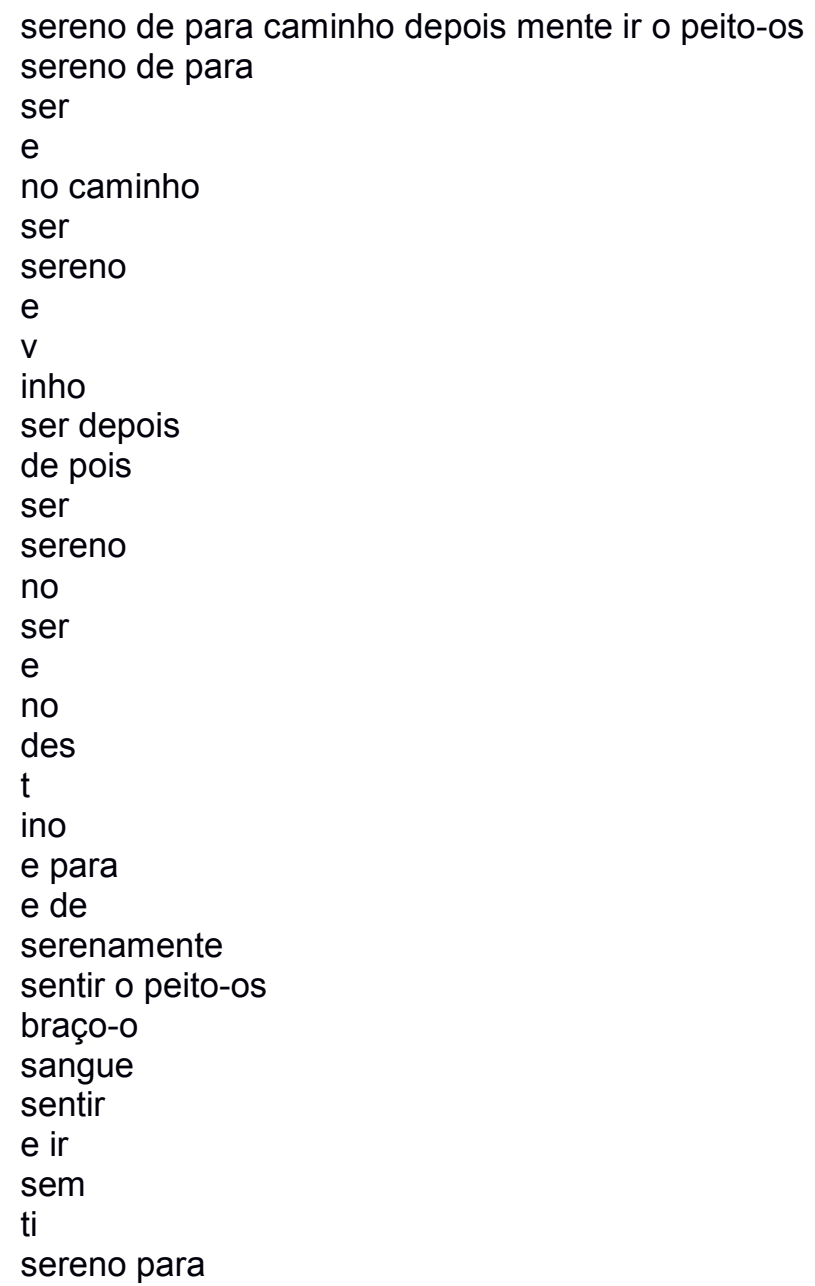




\section{Homeóstato 6}

Fig. 6 - Homeóstato 6, José-Alberto Marques, 1965. Imagem de Operação 1 (1967).

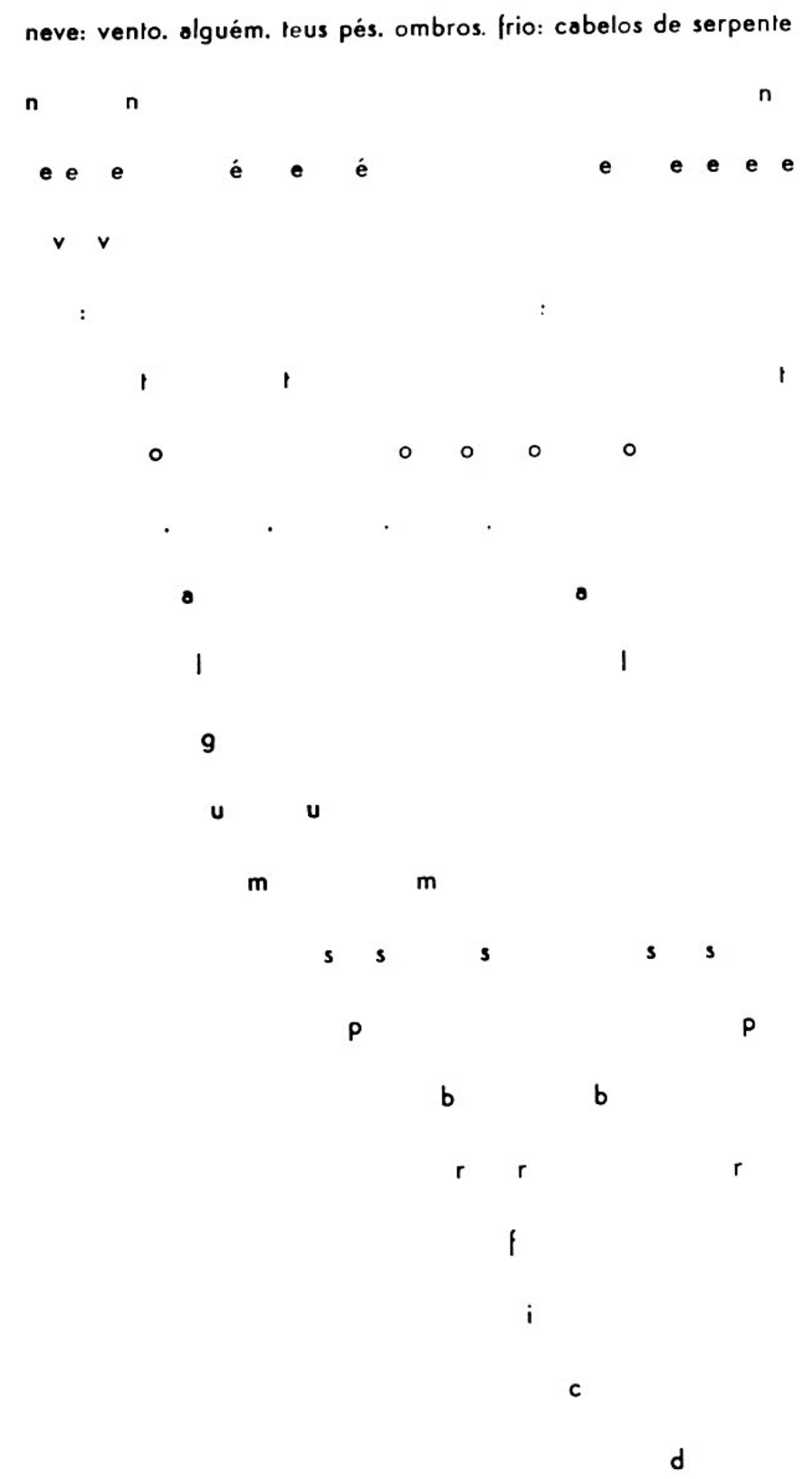

Texto Digital, Florianópolis, Santa Catarina, Brasil, v. 12, n. 1, p. 144-164, jan./jun. 2016. ISSNe: 1807-9288. 
Descrição: 21 iterações do verso: "neve: vento. alguém. teus pés. ombros. frio: cabelos de serpente" 


\section{Homeóstato 7}

Fig. 7 - Homeóstato 7, José-Alberto Marques, 1965. Imagem de Operação 1 (1967).

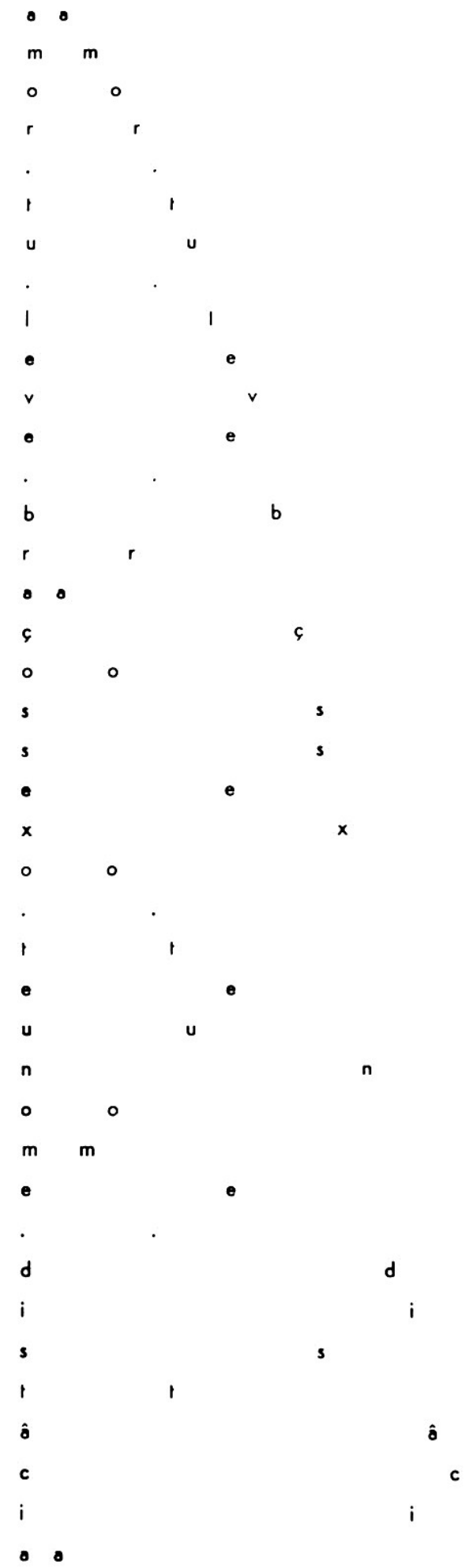

Texto Digital, Florianópolis, Santa Catarina, Brasil, v. 12, n. 1, p. 144-164, jan./jun. 2016. ISSNe: 1807-9288. 
Descrição: Homeóstato vertical, com 41 linhas, construindo o verso: "amor. tu. leve. braços sexo. teu nome. distância" 


\section{Homeóstato 8}

Fig. 8 - Homeóstato 8, José-Alberto Marques, 1965. Imagem de Operação 1 (1967). Também publicado em Antologia da Poesia Concreta em Portugal (1973); Antologia da Poesia Experimental Portuguesa Anos 60 - 80 (2004).

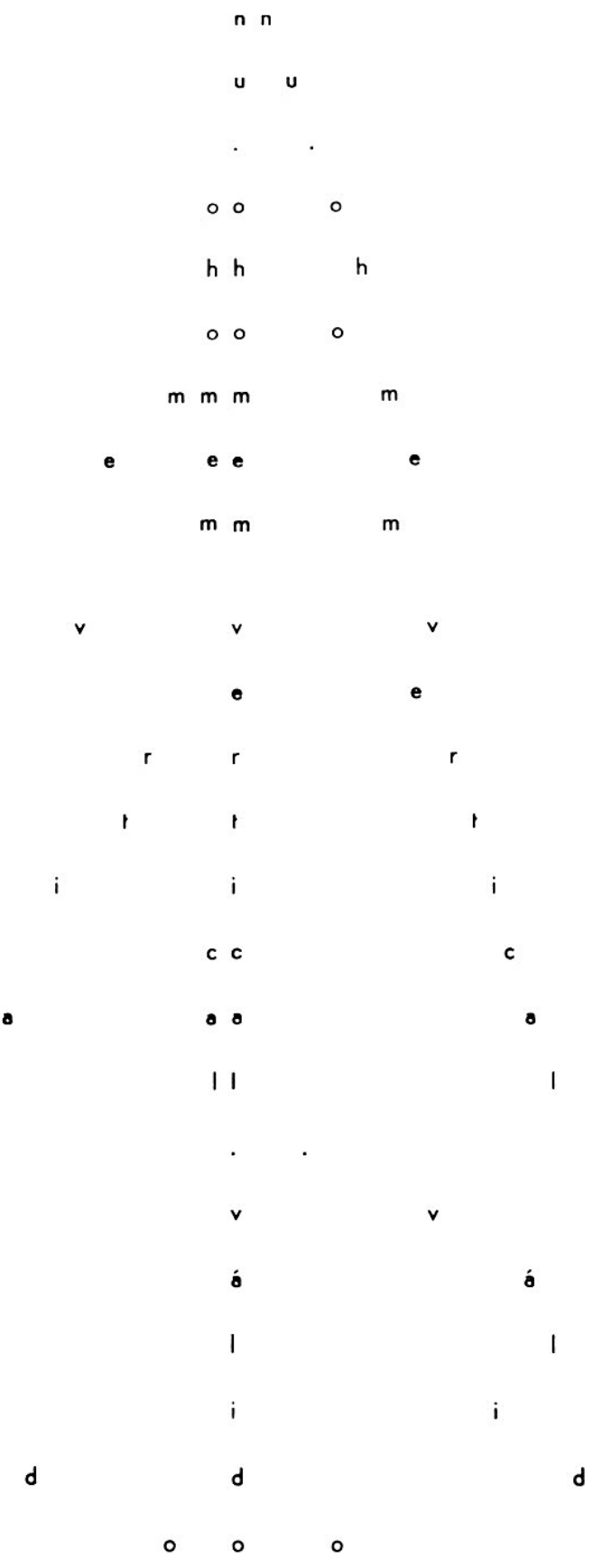

Texto Digital, Florianópolis, Santa Catarina, Brasil, v. 12, n. 1, p. 144-164, jan./jun. 2016. ISSNe: 1807-9288. 
Descrição: Homeóstato de leitura vertical, a partir do centro, 24 linhas construindo o verso: "nu. o homem vertical. válido" 


\section{Homeóstato 9}

Fig. 9 - Homeóstato 9, José-Alberto Marques, 1965. Imagem de Operação 1 (1967). Também publicado em Antologia da Poesia Concreta em Portugal (1973).

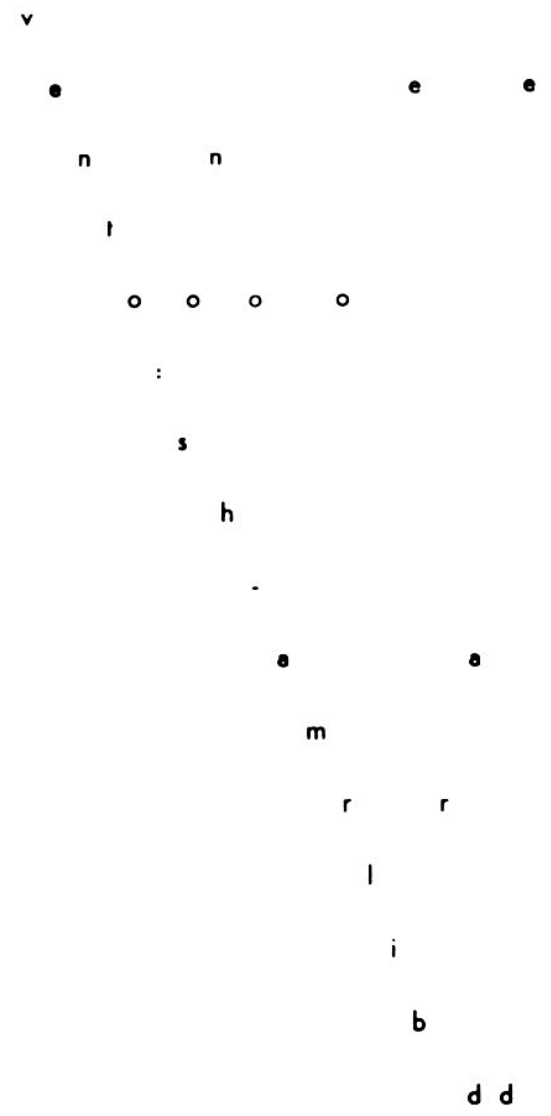

Texto Digital, Florianópolis, Santa Catarina, Brasil, v. 12, n. 1, p. 144-164, jan.jjun. 2016. ISSNe: 1807-9288. 
Descrição: Homeóstato de leitura diagonal, a partir da esquerda, 16 linhas com "vento: sh-amrlibd". Jogo final com as palavras liberdade e amor. 


\section{Homeóstato A}

Fig. 10 - Homeóstato A, José-Alberto Marques, 1993. Imagem de Imaginários de ruptura (2002).

a secura da pedra da catedral antiga tem veios na garganta e escuta a voz inisteriosa do silêncio que ao soar reflecte o vento do tempo, do tempo em

0 grito lento

a
a a
a a

a

e

e

0

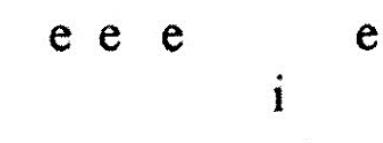

$0 \quad 0 \quad 0 \quad 0$

II

a secura da pedra

a

a

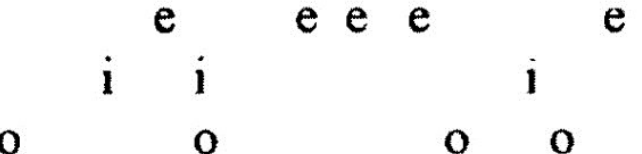

a voz misteriosa

a $\quad$ a $\quad$ a $\quad$ a

$\begin{array}{llllll}\text { e e } & \text { e } & & & \text { e } \\ & & \text { i } & & \\ & & 0 & 0 & 0\end{array}$

u reflecte

a

a a a a

a

e

e

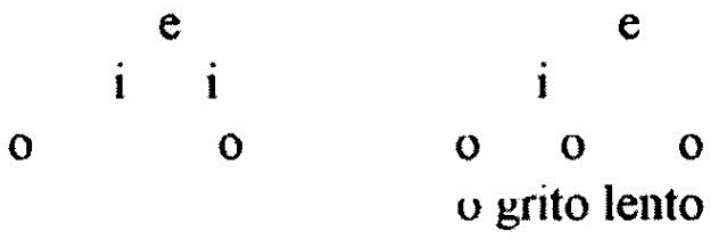

a

a a a a e

e<smiles>[Li]C=CC</smiles>

0

0

$\mathbf{u}$ 
Descrição: 27 linhas, com vogais (a, e, i, o, u), com realce para "a secura da pedra/ a voz misterirosa/ reflecte/ o grito lento", à volta da repetição de:

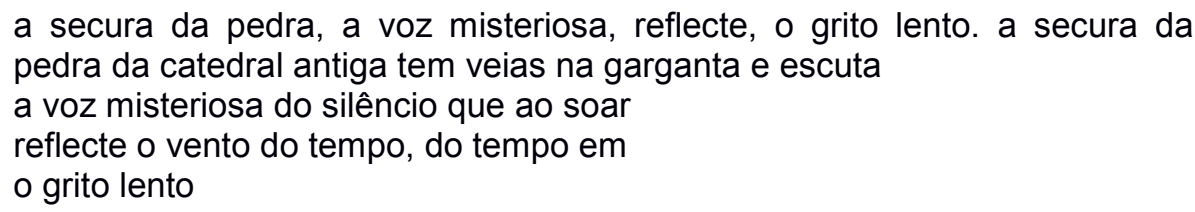

10 HOMEÓSTATOS BY JOSÉ-ALBERTO MARQUES [FOLLOWED BY TEXTUAL TRANSCRIPTION]

ABSTRACT: Homeóstatos, by José-Alberto Marques (1965-2002).

KEYWORDS: Homeóstatos. José-Alberto Marques. Portuguese Experimental Poetry.

\section{Referências}

AGUIAR, Fernando; MAXIMINO, Jorge. (Orgs.). Imaginários de ruptura. Lisboa: Instituto Piaget, 2002.

ARAGÃO, António; MELO E CASTRO, E. M. de; HELDER, Herberto. (Orgs.). Poesia Experimental: $2^{\circ}$ caderno antológico. Lisboa, s.n., 1966.

MARQUES, José Alberto; MELO E CASTRO, E. M. De. (Orgs.). Antologia da Poesia Concreta em Portugal. Lisboa: Assírio \& Alvim, 1973.

MELO E CASTRO, E. M. De. (Orgs.). Operação 1. Lisboa: s.n., 1967.

SOUSA, Carlos Mendes; Ribeiro, Eunice. (Orgs.). Antologia da Poesia Experimental Portuguesa Anos 60 - 80. Coimbra: Angelus Novus, 2004. 